\title{
Exercise Professionals - Could they be the Forgotten Public Health Resource in the War against Obesity?
}

\section{Oprescu F*, McKean M and Burkett B}

School of Health \& Sports Science, Faculty of Science, Health, Education and Engineering, University of the Sunshine Coast, Australia

Keywords: Personal trainer; Sport as medicine; Obesity; Public health

\section{Introduction}

Obesity continues to develop worldwide creating a burden on both communities and health care. Obesity impacts not only on the health of the individual but also on the populations in many countries. There is a general push to further develop the idea that 'Exercise is Medicine' encouraging more of the population to develop exercise habits with the aim to prevent obesity and fight lifestyle disease. However questions remain regarding the means by which this message will be disseminated as well as the personnel responsible for delivering this message.

\section{Exercise professionals as a public health and health promotion resource}

Health promotion is the science and art of enabling people and communities to have more control over their health and lives. The potential of Exercise Professionals as a key health promotion resource, as a bridge between sport and health, is still to be fully recognised. Thus, greater understanding of the potential role, impact and influence that Exercise Professionals can have in the war against obesity and chronic disease needs to be immediately pursued through research, consultations and professional collaborations.In this paper we will outline some findings and recommendations regarding the potential of Exercise Professionals of playing a key role in health promotion and disease prevention.

Scientific literature indicates that obesity and associated chronic diseases are a major burden on the populations and health systems of many countries $[1,2]$. There are many complex issues around obesity and chronic diseases such as:

1. Increased morbidity and mortality due to preventable chronic diseases $[3,4]$

2. Failure of health care systems, including public health, to address the growing obesity epidemic and its associated morbidity [2]

3. Nutritional risk factors and reduced physical activity contributing to a high proportion of the aforementioned burdens across gender, age and socio economic status [1,4-6]

The real challenge lies not in documenting problems, but in finding solutions to reduce the burden of obesity and chronic diseases, preferably sustainable solutions for which resources are already available and need not be invented[7]. Various inter professional strategies including Exercise Professionals as a key player in the health promotion team can be used to enhance physical activity and nutrition for elite athletes $[8,9]$ as well as general populations $[10,11]$. Six examples are included below:

1. Providing incentives to physicians to prescribe exercise and refer patients to Exercise Professionals, while lowering the cost of such interventions [6].

2. Development and use of shared evidence-based guidelines between Exercise Professionals, nutritionists, and public health professionals [1,12].
3. Enhancing communication and trust between Exercise Professionals and their clients through education and availability of evidence-based guidelines [12].

4. Providing financial incentives to reduce barriers and encourage increased participation in supervised physical activity, especially in at risk populations [11].

5. Enabling community health workers and other health promotion professionals to encourage and sustain community-based physical activity supervised by Exercise Professionals [13].

The potential impacts of Exercise Professionals as health promotion and disease prevention resource are summarised next:

1. Play an active role in the development of social norms and role models that encourage regular physical activity [13].

2. Early identification of at risk populations and their risk factors (injury, weight, medical conditions, nutritional \& hydration risk factors) [1,9].

3. Expand primary care scope of practice roles for Exercise Professionals (health promotion \& disease prevention plus non-traditional medical services referral) [9].

4. Enhance the functionality and capacity of primary care and community networks through engagement with multidisciplinary health teams in order to provide solutions to the growing problem of chronic diseases $[1,10,11]$.

5. Reduce the overall burden on hospital admissions due to preventable conditions [14].

6. A healthier population in the long term [14].

To ensure that impacts can be documented, they need to be tracked. As such better data collection may be necessary. Three strategies related to data collection and impact evaluation are available:

1. Collect and report data on Exercise Professional services access and utilisation, including variables such as age, ethnicity, socioeconomic status, and language.

2. Include measures of referral sources, client longevity and attrition rates in assessing provider performance.

*Corresponding author: Oprescu F, Lecturer Health Promotion - School Health \& Sport Sciences, University Sunshine Coast, Locked Bag 4, Maroochydore DC Queensland, 4558 Australia, Tel: +61 075459 4639; Fax: +61 75456 4600; E-mail: foprescu@usc.edu.au

Received August 18, 2012; Accepted August 18, 2012; Published August 21 2012

Citation: Oprescu F, McKean M, Burkett B (2012) Exercise Professionals - Could they be the Forgotten Public Health Resource in the War against Obesity? J Sports Med Doping Stud 2:e122. doi:10.4172/2161-0673.1000e122

Copyright: ( 2012 Oprescu F, et al. This is an open-access article distributed under the terms of the Creative Commons Attribution License, which permits unrestricted use, distribution, and reproduction in any medium, provided the original author and source are credited. 
3. Monitor progress using individual and population level measures [15].

However there are several concerns with respect to the role of the Exercise Professionals and their skills. Research suggests that even though giving nutritional and health advice may not be in the contractual domain of the Exercise Professional, advice was still provided and appeared to be an acceptable process and Exercise Professionals may feel drawn to assume a widening definition of their expertise [16]. The client-Exercise Professional relationship appears to also be a complex one. It has been reported that there are often financial incentives for the professional in the product they refer to their clients which can create a bias away from accepted nutritional recommendations [10]. Concerns have also been raised that the title 'Personal Trainer' can be assumed by anyone regardless of qualifications making it difficult for the general public to determine the difference [17]. Furthermore there is little evidence that Exercise Professional certifications actually include health promotion therefore questioning the ability of the Exercise Professional to take on this role. Thus, as a first step in this direction, it may be warranted to determine the current relationship that exists between the Exercise Professional and population with respect to nutrition advice and health guidance.

\section{Conclusion}

Existing evidence suggests that Exercise Professionals could play a much more significant role from a health promotion perspective. With proper education [12], Exercise Professionals could be a key resource for health promotion and disease prevention in many countries [18]. For the future we invite our colleagues from various disciplines and professions to generate additional answers to the question: how can scholars, academics, policymakers and other key stakeholders ensure that Exercise Professionals have the opportunity to contribute their full potential to the health of populations?

\section{References}

1. Nowicka P (2005) Dietitians and exercise professionals in a childhood obesity treatment team. Acta Paediatr Suppl 94: 23-29.

2. Zhuo C, Kakoli R, Anne CH, Stephen BT (2010) Factors associated with differences in mortality and self-reported health across states in the United States. Health policy 94: 203-210.
3. Roger VL, Go AS, Jones DML, Adams JR, Berry JD, et al. (2011) Heart Disease and Stroke Statistics-2011 Update. Circulation 123: e18-e209.

4. Adler NE, Stewart J (2010) Health disparities across the lifespan: Meaning methods, and mechanisms. Ann N Y Acad Sci 1186: 5-23.

5. Salihu HM, Bonnema SM, Alio AP (2009) Obesity: What is an elderly population growing into? Maturitas 63: 7-12.

6. Cobiac LJ, Vos T, Barendregt JJ (2009) Cost-Effectiveness Of Interventions To Promote Physical Activity: A Modelling Study. PLoS Med 6: e1000110.

7. Terry TTK, Story MT (2010) A Journey Just Started: Renewing Efforts To Address Childhood Obesity. Obesity 18: S1-S3.

8. Whitson E, Cordova ML, Demchak T, Stemmans CL, King KA (2006) Certified athletic trainers' knowledge and perception of professional preparation involving eating disorders among athletes. J Allied Health 35: 18-29.

9. Bonci CM, Bonci JL, Granger LR, Johnson CL, Malina RM, et al. (2008) Nationa Athletic Trainers' Association Position Statement: Preventing, Detecting, And Managing Disordered Eating In Athletes. J Athl Train 43: 80-108.

10. Jeffery RW, Wing RR, Thorson C, Burton LR (1998) Use of personal trainers and financial incentives to increase exercise in a behavioral weight-loss program. J Consult Clin psychology 66: 777-783.

11. Davis L, Loyo K, Schwertfeger R, Glowka A, Danielson L, et al. (2009) A Comprehensive Worksite Wellness Program in Austin, Texas: Partnership Between Steps to a Healthier Austin and Capital Metropolitan Transportation Authority. Prev Chronic Dis 6: A60.

12. Dawn S, Hopkins M, Adamo BK, Shorr R, Prud'homme D (2010) Knowledge translation to fitness trainers: A systematic review. Implementation Science 5 28.

13. Fischer DV, Bryant $\mathrm{J}$ (2008) Effect of certified personal trainer services on stage of exercise behavior and exercise mediators in female college students. J Am Coll Health 56: 369-376.

14. Rose SB, Lawton AB, Elley CR, Dowell AC, Fenton AJ (2007) The 'Women's Lifestyle Study', 2-year randomized controlled trial of physical activity counselling in primary health care: rationale and study design. BMC Public Health 7:166.

15. Heath GW (2009) The role of the public health sector in promoting physica activity: national, state, and local applications. J Phys Act Health 6: S159-S167.

16. Gavin J (1996) Personal trainers' perceptions of role responsibilities, conflicts and boundaries. Ethics and Behavior 6: 55-69.

17. Rupp J, Kathy C, Walter RT, Donna T (1999) Professional Preparation of Personal Trainers. JOPERD--The Journal of Physical Education, Recreation \& Dance 70 : 54-57.

18. Hare SW (2000) Attitudes and perceptions of fitness professionals regarding obesity. J Community Health 25: 5-21. 